\title{
Article
}

\section{Body size, skeletal maturity and functional characteristics of elite academy soccer players on entry between 1992 and 2003}

Carling, C., Le Gall, F., and Malina, R.M.

Available at http://clok.uclan.ac.uk/12297/

Carling, C. ORCID: 0000-0002-7456-3493, Le Gall, F., and Malina, R.M. (2012) Body size, skeletal maturity and functional characteristics of elite academy soccer players on entry between 1992 and 2003. Journal of Sports Sciences, 30 (15). pp. 1683-1693. ISSN 0264-0414

It is advisable to refer to the publisher's version if you intend to cite from the work. http://dx.doi.org/10.1080/02640414.2011.637950

For more information about UCLan's research in this area go to http://www.uclan.ac.uk/researchgroups/ and search for <name of research Group>.

For information about Research generally at UCLan please go to http://www.uclan.ac.uk/research/

All outputs in CLoK are protected by Intellectual Property Rights law, including Copyright law. Copyright, IPR and Moral Rights for the works on this site are retained by the individual authors and/or other copyright owners. Terms and conditions for use of this material are defined in the policies page.

\section{CLoK}

Central Lancashire online Knowledge www.clok.uclan.ac.uk

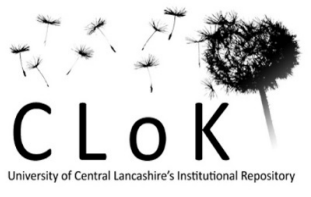


This is a pre-proof corrected manuscript, as accepted for publication, of an article published by Taylor \& Francis in Journal of Sports Sciences on $31^{\text {st }}$ January 2012, available online: http://www.tandfonline.com/doi/abs/10.1080/02640414.2011.637950?url_ver=Z39.882003\&rfr_id=ori:rid:crossref.org\&rfr_dat=cr_pub\%3dpubmed\#.VbdzoE3bLcs

PLEASE REFER TO THE PUBLISHED VERSION FOR CITING PURPOSES

\title{
Body Size, Skeletal Maturity and Functional Characteristics of Elite Academy Soccer Players
} on Entry between 1992 and 2003

\author{
Christopher Carling ${ }^{1,2}$ \\ Frank. Le Gall ${ }^{1}$ \\ Robert M. Malina ${ }^{3}$
}

${ }^{1}$ LOSC Lille Métropole Football Club, Domain de Luchin, Camphin-en-Pévèle, France

${ }^{2}$ Institute of Coaching and Performance, University of Central Lancashire, Preston, United Kingdom ${ }^{3}$ Professor Emeritus, Department of Kinesiology and Health Education, University of Texas at Austin and Research Professor, Tarleton State University, Stephenville, Texas

Corresponding author:

Christopher Carling

LOSC Lille Métropole Football Club, Domain de Luchin, Camphin-en-Pévèle, France.

Tel: +33 603921863 


\begin{abstract}
Secular changes in body size, estimated fatness, skeletal maturation and functional characteristics of youth soccer players on entry into an elite academy between 1992 and 2003 were compared. Annual selections grouped across time (1992-1995, 1996-1998, 1999-2003), playing position (goalkeeper, defender, midfielder, forward), and by eventual status in the sport (professional, non-professional) were compared. Data for 158 players (13.4 \pm 0.4 years) at entry into the academy included skeletal age (Greulich-Pyle method), height, weight, relative fatness, four field tests of functional capacities (aerobic, anaerobic, power, speed) and quadriceps concentric strength of the dominant and non-dominant legs. MANCOVA with age as the covariate and chi square were used for comparisons across years. With few exceptions notably estimated $\dot{\mathrm{V}} \mathrm{O}_{2 \mathrm{max}}$, results for player size, functional characteristics and skeletal maturation did not differ among years. Distributions of players by skeletal maturity status and within each playing position also did not differ between years. Although related research has suggested that the anthropometric characteristics of professional players and demands of contemporary professional soccer competition increased over this period, the size, maturity and functional characteristics of youth players on entry to an elite academy and of graduates who eventually played soccer at the professional level generally did not change across annual selections from 1992-2003. The results suggest a lack of change in selection philosophies and practices of coaches involved in recruiting players for the academy which in turn is reflected in consistency of specific evaluation criteria employed over the decade considered.
\end{abstract}

\title{
Key Words
}

skeletal age, maturation, young athletes, talent identification, association football 


\section{Introduction}

Soccer clubs throughout the world recruit youth into their programmes on a regular basis. Although practices vary among clubs and by levels of competition, the goal is ultimately to identify and select talented or potentially talented players. Many countries have national programmes and centres devoted to this purpose followed by selection into systematic programmes for developing playing skills and tactics, and nurturing the individual towards realising potential already predicted (Reilly, Williams, Nevill \& Franks, 2000; Meylan et al., 2010). The initial process of identifying promising soccer players is multifaceted and complex. Nevertheless, anthropometric, maturation and fitness characteristics are commonly used in talent identification schemes as predictors of performance that predispose promising players toward selection into elite soccer development programmes and eventual progress to higher echelons of play (Carling et al., 2010; Vaeyens et al., 2006; Williams \& Reilly, 2000).

In general, youth soccer players present above average values for height, mass and tend to be advanced in biological maturity status with increasing age during adolescence and in elite development programmes (Malina, 2003, 2011). Lower baseline anthropometric and functional performance measures have generally been observed in youth soccer players who either dropped out (Figueiredo et al., 2009) or who were not selected to play at the next level (Gil et al., 2007) compared to those moving to a higher playing standard. Similar findings were noted in elite academy players who on eventual graduation were not offered a professional contract compared to those awarded a contract (le Gall et al., 2010). Although these physical attributes are not necessarily retained throughout maturation or automatically translated into exceptional performance in adulthood (Vaeyens et al., 2008), the net result is that select populations of purported 'physically' talented young soccer players enter elite academy development programs every year.

It is possible, nevertheless, that physical characteristics of players vary across annual selections on entry depending on real and/or perceived needs of elite development programmes. However, there is no evidence of changes over time in baseline anthropometric and fitness features or maturity status in youth 
soccer players recruited into high-level development programmes. Physical predispositions also vary among different playing positions within elite youth soccer (le Gall et al., 2010; Reilly, Bangsbo \& Franks, 2000). It would make sense, therefore, to investigate temporal changes in baseline physical features of players. This information may potentially assist practitioners in determining whether general and/or position-specific fitness characteristics in players entering elite programmes have evolved. It would also enable assessment of the value of current recruitment criteria, notably biological requisites, and ensuing physical development programmes. Recent and substantial increases in height and body mass of professional soccer players (Nevill, Holder \& Watts, 2009) combined with an upward trend in the physical demands of contemporary professional match-play (Carling et al., 2008; Cazorla et al., 2009) inform the need for an analysis of changes over time in physical characteristics at youth level. Thus, the purpose of this paper is to evaluate the body size, estimated fatness, skeletal maturation and functional characteristics of youth soccer players on entry into an elite academy between 1992 and 2003. It specifically compares players across time and by skeletal maturity status and position, and also compares baseline characteristics of players by eventual status in the sport.

\section{Methods}

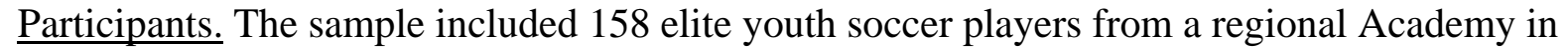
France. All participants were tested on entry between 1992 and 2003. Participants gave their assent to participate in the study and consent forms were completed for each participant by a parent or guardian as players were under the legal age of consent. The study was approved by the ethics committee of the French Football Federation. This study revisits a dataset used in two previous studies of anthropometric and fitness characteristics in players from the present academy (le Gall et al., 2008; Carling et al., 2009).

Players had to have a minimum age of 13 years on entry. Before 1996, the cut-off date for selection in youth soccer in France ran from 1 August to July 31. After 1996, cut-off dates for the selection year extended from 1 January to 31 December. Although a larger number of players entered the academy, the 
study was limited to 158 with complete data for skeletal maturation, anthropometry and four field tests of functional capacities (aerobic, anaerobic, power, speed). Of this sample, 146 players had complete data for measures of quadriceps strength of the dominant and non-dominant legs. All variables were measured on entry to the academy, prior to the preseason training period as part of each player's physical examination and development programme.

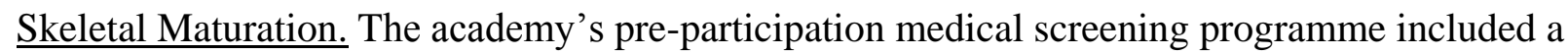
radiograph of the left hand and wrist for assessment of skeletal maturity status. The Greulich-Pyle method (Greulich and Pyle, 1959) was used to estimate skeletal age. The protocol requires matching the handwrist radiograph of the player to standard plates for the reference sample in the Greulich-Pyle atlas. Skeletal age represents the chronological age at which a specific level of maturation of the hand-wrist bones was attained by the reference sample upon which the method of assessment was developed (Malina et al., 2004a; Malina, 2011). Films were evaluated by the Institute physician. Radiographs of 15 randomly selected players were re-assessed six months after initial assessments. The mean difference and correlation between assessments were $0.10 \pm 0.14$ year and 0.94, respectively (le Gall et al., 2007).

The chronological age of each player was calculated as the difference between the date of the radiograph and date of birth. The ratio of skeletal age to chronological age was calculated for use in the statistical analyses; the ratio eliminates negative values. The difference between skeletal age and chronological age (skeletal age minus chronological age) was used to classify players in categories of maturity status as follows:

Skeletal age within \pm 1.0 year of chronological age, on time (average);

Skeletal age behind chronological age by more than 1.0 year, late (delayed);

Skeletal age in advance of chronological age by more than 1.0 year, early (advanced). This classification was similar to previous studies of athletes and non-athletes using the difference between skeletal age and chronological age (Malina, 2011). The band of \pm 1.0 year also approximates standard deviations of skeletal ages within specific chronological age groups. Means of age-specific standard 
deviations between 10 and 17 years in studies using the Greulich-Pyle and other methods of assessment are slightly $>1.0$ year in males and $<1.0$ year in females, while means for sexes combined approximate 1.0 year (Malina, 2011). A band of \pm 1.0 year also allows for error associated with assessments.

Anthropometry. Height $(\mathrm{cm})$ was measured with portable anthropometer (Holtain, Instruments Ltd, Crymych, United Kingdom). Weight (kg) was measured on regularly calibrated precision scales. Four skinfolds (triceps, biceps, subscapular, suprailiac) were measured with a Harpenden skinfold calliper (British Indicators Ltd, Luton, Uk). The four skinfolds were used to estimate percentage body fat (\% Fat) with the equations of Durnin and Womersley (1974).

Functional capacities. Four field tests (running speed, muscular power, aerobic endurance and anaerobic power) and a laboratory test of knee strength were administered. The tests were performed at the same time of day, in the same order and with the same apparatus. Each test was preceded by a standardised warm-up and familiarisation session. Participants were instructed to refrain from strenuous exercise for at least $48 \mathrm{~h}$ prior to the fitness test session and consume their normal pre-training diet prior to the session. All procedures over the entire study period were undertaken by the same sports physician.

Running speed was measured from a standing start over distances of $10 \mathrm{~m}, 20 \mathrm{~m}$, and $40 \mathrm{~m}$, respectively, using single-beam electronic timing gates (Tag Heuer, Switzerland). Two trials with a 10minute interval were administered. The better of the two trials for the 40-m effort was retained for analysis (along with the corresponding times over $10 \mathrm{~m}$ and $20 \mathrm{~m}$ ).

Estimated maximal anaerobic power output was calculated from the recorded time over the last 10$\mathrm{m}$ of the fastest 40-m sprint (Le Gall et al., 2008).

The vertical jump was the indicator of lower-body explosive strength using a Bosco jump mat (Ergojump, Magica, Italy). A countermovement jump with arm-swing but without a run-up was used. The best of three double leg vertical jumps was retained for analysis.

$\dot{\mathrm{V}} \mathrm{O} 2 \mathrm{max}$ was estimated with a 20-m continuous progressive track run test for the measurement of maximal aerobic speed ( $\mathrm{vVO}_{2 \max }$, Chtara et al., 2005). Testing took place on a $400 \mathrm{~m}$ track with cones 
placed every $20 \mathrm{~m}$. A pre-recorded soundtrack indicated with beep sounds the instant when the player had to pass near a cone to maintain the required speed. A longer sound marked a change of stage. The first stage was set at $8 \mathrm{~km} \cdot \mathrm{h}^{1}$ with subsequent increments of $0.5 \mathrm{~km} \cdot \mathrm{h}^{-1}$ per 1 -min stage. The test was concluded when the player was unable to maintain the required running speed. The speed corresponding to the last completed stage was recorded as $v \dot{\mathrm{V}} \mathrm{O}_{2 \max }\left(\mathrm{km} \cdot \mathrm{h}^{-1}\right)$ which was then used to estimate $\dot{\mathrm{V}} \mathrm{O}_{2 \max }$.

The strength of the quadriceps of the dominant and non-dominant legs was measured on a Cybex 340 isokinetic dynamometer (Cybex, New York, USA). Strength was assessed as peak concentric torque at 1.05 and 4.19 rad. $\mathrm{s}^{-1}$. Three maximal voluntary repetitions were undertaken with the order proceeding from slower to faster speeds. The best trial for each was retained for analysis.

Playing Status. Information of the eventual playing status of those selected for the academy was obtained from the French Professional Football League (http://www.lfp.fr/). Players who signed a contract with a professional club and played at least one game at professional level were designated professional; the remainder was designated non-professional.

Analysis. Data for skeletal age, body size, \% Fat, $\dot{\mathrm{V}} \mathrm{O} 2 \mathrm{max}$, vertical jump, sprints and anaerobic power were available for the total sample of 158 players. Observations for concentric strength of the quadriceps were lacking for 12 players. Hence, separate analyses were done for the quadriceps strength measures on 146 players.

Descriptive statistics were calculated by year for all variables. Numbers of players were small in 1992 and 1993 and 2000 to 2003; the data for the respective years were thus combined. Chronological age

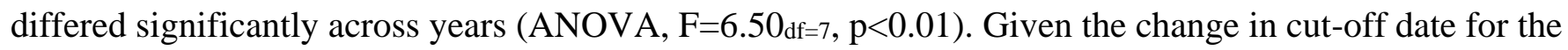
selection year in 1996 and to increase statistical power, players were combined into three groups between 1992 and 2003 for subsequent secular comparisons: 1992-1995 (n=49), 1996-1998 (n=74), and 1999-2003 $(n=35)$. Players selected before 1996 were significantly older $(13.8 \pm 0.2$ years $)$ than players born between

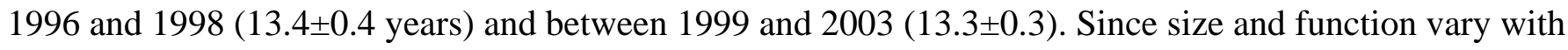


chronological age during male adolescence (Malina et al., 2004), MANCOVA with chronological age as the covariate was used for comparison of secular change among the three groups.

The chi square statistic was used to compare distributions of players by skeletal maturity status (late, on time and early) in the three selection periods, i.e., 1992-1995, 1996-1998 and 1999-2003. Chronological age, body size, relative fatness and functional characteristics of players in the contrasting maturity groups in the three groups were compared with MANOVA. Since maturity-associated variation in body size status influences functional characteristics during male adolescence (Malina et al., 2004a), functional characteristics among players in the three maturity groups over time were also compared with MANCOVA with the chronological age, height and weight as covariates.

Players were grouped by position: goalkeepers, defenders, midfielders and forwards. The chi square statistic was used to compare distributions of players by position in the three selection periods, i.e., 1992-1995, 1996-1998 and 1999-2003. MANOVA was used to compare player characteristics by position across the three groups spanning 1992-2003. Allowing for maturity-associated variation per se and in body size, MANCOVA with the skeletal age-chronological age ratio, height and weight as covariates was also used to compare functional characteristics of players by position.

Baseline characteristics of players who signed contracts with professional clubs and those who did not were also compared with MANOVA.

Bonferroni adjustments were used for all pairwise comparisons given a significant $F$ ratio. SPSS (version 14.0) was used for all analyses. A probability of $\mathrm{p}<0.05$ was accepted. The practical significance of reported statistical differences in means between groups was investigated using Effect Sizes (ES) calculated in a spreadsheet developed by Hopkins (2007). The criteria used to interpret the magnitude of Cohen's d were: $\leq 0.2$ trivial, $>0.2-0.6$ small, >0.6-1.2 moderate, $>1.2$ large (Hopkins, Marshall, Batterham, \& Hanin, 2009).

\section{Results}


Variation by Year. Descriptive statistics for player characteristics by year are summarised in Table 1. Results of the MANCOVA, with age as the covariate, comparing characteristics across time (i.e., the three groups spanning 1992-2003) are summarised in Table 2. Main effects for time were significant for skeletal maturity, body size, \% Fat and field tests of functional capacity $(\mathrm{F}=2.33 \mathrm{df}=24$, Wilks' $\lambda=0.699$, $\mathrm{p}=0.001)$ but not for the laboratory tests of quadriceps strength $\left(\mathrm{F}=0.73_{\mathrm{df}=8}\right.$, Wilks' $\left.\lambda=0.959, \mathrm{p}=0.661\right)$.

With few exceptions, player characteristics did not differ significantly among groups time interval considered. \% Fat differed significantly across time, but only one pairwise comparison was significant $(1992-1995,12.9 \pm 0.4 \% ; 1999-2003,11.5 \pm 0.4 \%$, p<0.05, ES=0.48). Estimated $\dot{V} \mathrm{O} 2 \mathrm{max}(\mathrm{ml} / \mathrm{kg} / \mathrm{min})$ in the 1999-2003 selections $(59.7 \pm 0.5)$ was significantly higher than estimates for $1992-1995(56.9 \pm 0.5, \mathrm{p}<0.01$, $\mathrm{ES}=0.86)$ and 1996-1998 (58.0 $\pm 0.4, \mathrm{p}<0.05, \mathrm{ES}=0.28)$. Although the 40-m sprint differed significantly among the three groups, none of the post hoc comparisons was significant $(\mathrm{p}>0.05)$. Given the few significant differences among years, players were combined across years for comparisons of player characteristics by skeletal maturity status and by position.

Variation by Maturity Status. The distribution of players by skeletal maturity status did not differ among the three groups spanning $1992-2003\left(\chi^{2}=4.12 \mathrm{df}=4, \mathrm{~ns}\right)$. Overall, $62 \%$ of players were on time (average), while $16 \%$ were late and $22 \%$ were early maturing. Characteristics of players by maturity status and results of the MANOVA are shown in Table 3. Main effects for maturity status were significant for chronological age, body size, $\%$ Fat and field tests of functional capacity $(F=5.73 \mathrm{df}=20$, Wilks' $\lambda=0.516$, $\mathrm{p}<0.001)$ and for the laboratory tests of quadriceps strength $\left(\mathrm{F}=9.58_{\mathrm{df}=8}\right.$, Wilks' $\left.\lambda=0.616, \mathrm{p}<0.001\right)$. Comparisons of skeletal age and the skeletal age-chronological age difference highlight the maturity contrast among groups. Chronological age and $\dot{\mathrm{V}} \mathrm{O}_{2 m a x}$ did not differ among maturity groups. The difference for $\%$ Fat was borderline $(\mathrm{p}=0.06)$; the difference between early and late maturing players was significant (early $>$ late, $\mathrm{p}<0.05, \mathrm{ES}=0.56)$. All other variables differed significantly $(\mathrm{p}<0.001)$ among groups and post hoc comparisons indicated a significant gradient: early > on time > late (ES range for the differences: 0.19 - 3.67; the majority of ES are larger for comparisons of early versus late maturing 
players). When height and weight were statistically controlled (not shown), the overall effect of maturity status was not significant for the field tests of functional capacity $(F=1.01$, Wilks' $\lambda=0.910, p=0.443)$ and for quadriceps strength $(F=1.59$, Wilks' $\lambda=0.914, p=0.128)$. Results of the univariate tests indicated significant differences only in the $20 \mathrm{~m}$ and $40 \mathrm{~m}$ sprints, anaerobic power and strength of the preferred leg $(\mathrm{p}<0.05)$ persisted among maturity groups. After adjusting for body size, early maturing players performed significantly better $(\mathrm{p} \leq 0.05)$ than players maturing late and on time in the $20 \mathrm{~m}$ and $40 \mathrm{~m}$ sprints and strength of the preferred leg, while performances of players late and on time did not differ. Only the difference between players early and on time in skeletal maturation was significant for maximal anaerobic power $(\mathrm{p}<0.05)$.

Variation by Playing Position. Except for chronological age, there were no significant interactions for player characteristics between year of entry and playing position (not shown). Distributions of players by skeletal maturity status (late, on time, early) within each position also did not differ among the three

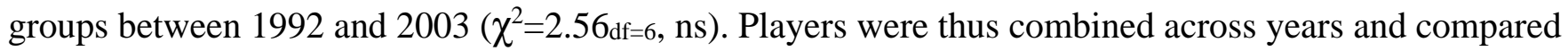
by position (Table 4). Main effects by position were significant for skeletal maturity, body size, \% Fat and field tests of functional capacity $(\mathrm{F}=2.63 \mathrm{df}=36$, Wilks' $\lambda=0.551, \mathrm{p}<0.001)$ and for tests of quadriceps strength $\left(\mathrm{F}=1.88_{\mathrm{df}=12}\right.$, Wilks' $\left.\lambda=0.854, \mathrm{p}<0.05\right)$. Chronological age and $\%$ Fat did not differ by position. All variables except for three strength measures differed significantly $(\mathrm{p}<0.01)$, but significance of post hoc comparisons differed among variables (ES range for the differences: 0.24-1.24).

Distributions of players by skeletal maturity status differed significantly by position $\left(\chi^{2}=14.62 \mathrm{df}=6\right.$, $\mathrm{p}<0.05)$. The majority of players in each position were on time in skeletal maturation. No goalkeepers were late maturing; most (78\%) were on time and the remainder was early. Distributions among defenders and forwards were similar. A bit more than one-half were on time (defenders, 55\%; forwards, 52\%), about one-third were early (defenders, 32\%; forwards, 30\%), and smaller percentages were late (defenders, 13\%; forwards, $18 \%$ ) maturing. Two-thirds of midfielders were on time in skeletal maturation (67\%), but proportionally more were late $(23 \%)$ than early $(10 \%)$ maturing. 
Since functional characteristics are potentially influenced by maturity status and body size, the comparison of players by position was replicated controlling for the maturity status (skeletal agechronological age ratio), height and weight. Results of the MANCOVA and adjusted means and standard errors are summarised in Table 5. All field tests of functional capacities differed significantly by position when maturity status, height and weight were statistically controlled $\left(\mathrm{F}=3.02_{\mathrm{df}=18}\right.$, Wilks' $\lambda=0.705$, $\mathrm{p}<0.001)$, while measures of quadriceps strength did not differ $(F=1.32 \mathrm{df}=12$, Wilks' $\lambda=0.893, \mathrm{p}=0.207)$. Adjusted means indicated higher $\dot{\mathrm{V}} \mathrm{O}_{2 \max }$ in midfielders compared to players in the other positions who did not differ (ES range: 0.18-1.22); better vertical jump performance in forwards than midfielders (ES: 0.69), while other pairwise position comparisons were not significant; greater anaerobic power in forwards, defenders and midfielders (who did not differ) than goalkeepers (ES range: 0.34-0.90); and faster sprints in forwards than players in the other three positions (ES range: 0.23-1.22), while other pairwise comparisons were not different.

Baseline Variation by Subsequent Playing Status. Baseline characteristics of players grouped by subsequent status in soccer (professional vs non-professional) are shown in Table 6. The overall effect of playing status was significant for chronological age, skeletal age, skeletal age-chronological age difference, body size, \% Fat and field tests of functional capacities $\left(F=3.49_{\mathrm{df}=13}\right.$, Wilks' $\left.\lambda 0.760, \mathrm{p}^{\circ}<0.001\right)$ but not for quadriceps strength $\left(\mathrm{F}=1.37_{\mathrm{df}=8}\right.$, Wilks' $\left.\lambda=0.926, \mathrm{p}=0.217\right)$. Results of univariate tests indicated that only height at baseline differed significantly between eventual professional and non-professional players $(\mathrm{p}<0.05, \mathrm{ES}=0.32)$. The differences in chronological age, weight and estimated $\dot{\mathrm{V}} \mathrm{O} 2 \mathrm{max}$ approached significance $(\mathrm{p}=0.07)$. Players who signed professional contracts were younger but taller and heavier, and had a higher estimated $\dot{\mathrm{V}} \mathrm{O}_{2 m a x}$ at baseline. \% Fat and other functional characteristics did not differ. Maturity status at baseline also did not differ among eventual professional (late 10, on time 48, early 10) and non-professional (late 16 , on time 50, early 24 ) players $\left(\chi^{2}=4.21_{\mathrm{df}=2, \mathrm{~ns}}\right)$. 
The present study is perhaps the first to examine variation in biological maturation status, and anthropometric and functional characteristics in annual selections of U-14 youth players on entry into a soccer academy for the elite over a decade, 1992-2003. Cut-off birth dates for the selection year changed during the decade (1996) and players selected in 1992, 1994 and 1995 were older (13.8 \pm 0.2 years) than players born in subsequent years (13.4 \pm 0.04 years). With few exceptions, however, player size, functional characteristics and skeletal maturation did not differ significantly among years. Distributions of players by skeletal maturity status (late, on time, early) also did not differ between years and within each position among years. The trends would suggest no significant differences in academy selection criteria across the years considered.

The majority of players on entry were classified as 'on time' (62\%) in skeletal maturity status, while players classified as late (delayed) and early (advanced) comprised $16 \%$ and $22 \%$ of the sample, respectively. The distribution of elite youth French players by skeletal maturity status at entry into the academy was consistent with observations among other samples of youth soccer players of the same age (Malina, 2011). Mean heights and weights of the French players were also consistent with observations of youth players the same age in Europe and the Americas (Malina, Coelho e Silva \& Figueiredo, in press). Mean height and weight of the players were at the respective $75^{\text {th }}$ percentiles of the reference for French youth (Sempé, 1995). Although mean weight was elevated relative to the reference, estimated \% Fat was similar to estimates for youth athletes in a variety of sports (Malina and Geithner, 2011).

As a whole, talent identification and selection schemes adopted by the academy appear to be heavily influenced by body size and maturity status and perhaps not on adult potential. Size and maturity status are related in adolescent boys and contrasts among boys classified as delayed (late) and advanced (early) in maturation are marked between 13 and 15 years (Malina et al., 2004a). Functional capacities are also related to maturity status and body size at these ages among adolescent boys in general (Malina et al., 2004a) and also in youth soccer players (Malina et al., 2004b; Cunha et al., 2011; Figueiredo et al., 2011). 
Soccer-specific technical skills are influenced by size and maturity status in youth soccer players, though to a lesser extent (Figueiredo et al., 2011; Malina et al., 2005, 2007a).

In addition to technical and tactical evaluation via drills and match-play, the anthropometric characteristics of players were measured and they performed functional speed and endurance-based tests as part of the different talent identification and selection stages run by the French Football Federation. Although size- and maturity-associated variation among U-14 players was highly apparent, it was likely that recruitment at different stages prior to final selection into the academy was also influenced by functional capacities and technical skills per se rather than simply by size and maturity alone.

Interrelationships among growth and maturity characteristics, functional characteristics and technical skills in the selection process require further investigation. The small proportion of later maturing players selected for the academy highlights a need for evaluation beyond immediate needs. Late maturing youth eventually reach maturity, and skilled but later maturing players may need to be nurtured through the system until maturity is attained (Meylan et al., 2010). This presents a challenge for those making early selection decisions.

The distribution of French academy players by skeletal maturity categories based on the GreulichPyle method (Greulich \& Pyle, 1959) was as follows: $16 \%$ late, $62 \%$ on time and $22 \%$ early, which was reasonably similar to that for a sample of regional and elite Portuguese and Spanish players $(\mathrm{n}=111$, 13.5 \pm 0.3 years) based on the Fels method (Roche, Chumlea \& Thissen, 1988): $8 \%$ late, $57 \%$ on time, $35 \%$ early). The corresponding distribution of maturity status based on the Tanner-Whitehouse 2 radius-ulnashort bone method (Tanner et al., 1983) in a larger sample of local to elite level players from Portugal, Spain, Belgium, Italy and Mexico ( $\mathrm{n}=246,13.5 \pm 0.3$ years) differs somewhat for players on time and early maturing: $13 \%$ late, $43 \%$ on time, $44 \%$ early (Malina, 2011). Although there was some variation among distributions of youth players by maturity status with three different methods of assessment of skeletal age, the trend towards a preference for on time and early maturing players was consistent. The difference in frequencies of players by maturity status reflected, in part, variation in methods of skeletal age assessment. 
The assessment protocols differ, especially for the later phase of maturation of the distal radius and ulna. Discussion of specific differences among methods is beyond the scope of this paper (see Malina et al., 2004a; Malina, 2011). Of relevance, skeletal ages with the three methods are related but not identical.

The French academy and regional and elite Portuguese-Spanish players did not differ in chronological age (13.5 \pm 0.4 and $13.5 \pm 0.3 \mathrm{yrs}$, respectively), but the French sample was, on average, taller (163.4 \pm 9.2 vs $159.9 \pm 8.5 \mathrm{~cm}$, respectively, and heavier (52.0 \pm 9.5 vs $49.8 \pm 8.9 \mathrm{~kg}$, respectively). Chronological ages did not differ among late, on time and early maturing players in the two samples, but French players on time and early in skeletal age were, on average, taller (on time 163.5 \pm 8.2 vs 158.0 \pm 6.9 cm; early $171.0 \pm 6.2 \mathrm{vs} 165.5 \pm 7.6 \mathrm{~cm}$ ) and heavier (on time $52.0 \pm 8.0 \mathrm{vs} 47.4 \pm 7.1 \mathrm{~kg}$; early $60.6 \pm 6.6 \mathrm{vs}$ $56.0 \pm 8.5 \mathrm{~kg}$ ). Late maturing players in the two samples did not differ in weight (French: $40.6 \pm 3.4$, Portuguese-Spanish: $39.9 \pm 4.4 \mathrm{~kg})$, while the former were taller $(152.9 \pm 5.1 \mathrm{vs} 149.1 \pm 5.1 \mathrm{~cm})$.

Differences in talent assessment criteria at youth levels among countries may contribute to some of the observed variation in size and maturation. An additional factor is population variation within Europe (Eveleth \& Tanner, 1990; Bodzsar \& Susanne, 1998). For example, mean heights of late adolescent/young adult males in 1990 were, respectively, $175.1,173.8$ and $171.4 \mathrm{~cm}$ in France, Spain and Portugal (Demoulin, 1998; Rebato, 1998; Padez 2003). Ethnic variation within a population is also a factor, although laws in the present and other European countries do not permit identification of the ethnicity of participants (Malina, 2009).

Evidence from motion analyses suggests that the physical demands of contemporary professional soccer match-play had evolved considerably over the previous two decades (Strudwick \& Reilly, 2001; Carling et al., 2008). In addition, an upward trend has been reported for the mean height and body mass of professional players in the top English League from 1993/94 to 2003/04 (Nevill, Holder \& Watts, 2009). Over a decade, player height and body mass increased by approximately $2 \mathrm{~cm}$ and $1.5 \mathrm{~kg}$ with the trend more apparent in successful teams (finishing in top-6 places). However, the size, maturity and functional characteristics of players on entry to the present centre and of participants who eventually played soccer at 
professional level generally did not differ across selections from 1992-2003. Maturity, anthropometric and fitness characteristics among players in the four playing positions also did not change over this interval. By inference, these reported changes in anthropometric features in professional players and the greater physical demands of contemporary professional soccer match-play over the same period seem not to have had an impact on the general and position-specific physical qualities required for selection into the present elite academy nor or on the characteristics of players eventually selected to play professionally.

Implications for Talent Selection and Development

The lack of a change in reference values in 10 annual samples of under-14 soccer players over a decade has provided strong clues as to the existence of biological prerequisites chosen by practitioners in talent identification programmes for entry in the present academy and for eventual selection to play professional soccer. These results might reflect a lack of change in selection philosophies of coaches involved in recruiting players for the academy and/or consistency in specific evaluation criteria employed over the study period. Interestingly, birth quarter distributions of the annual selections did not vary significantly across years $\left(\chi^{2}=23.97, \mathrm{~ns}\right)$. The majority of players were born in the first $(49 \%)$ and second $(29 \%)$ quarters of the selection year. Present selection policies were therefore not only systematically biased towards taller, heavier and more mature players especially when compared to the general population, but also discriminated against players born later in the selection year. In addition to aiding the identification and selection of potential talent, the battery of tests used as part of selection trials described earlier might therefore be seen to be employed as a marker to discriminate against a certain type of youth player. However, in the absence of physical data obtained from the test battery during these trials for youth players not selected for entry into the present academy combined with the lack of information addressing differences in technical, sociological and psychological characteristics, this theory remains unconfirmed. Nevertheless, while anthropometric and physical characteristics are seemingly appealing for initial talent identification and selection, their ability to successfully predict a subsequent professional career is 
debatable. Indeed, characteristics reported in the present players eventually selected to play professionally were generally similar to those observed in non selected peers. Further longitudinal programmes of research are required to establish the validity and usefulness of multidisciplinary test batteries across varying age groups, standards of ability and stages of selection. 


\section{References}

Bodzsar, E.B., \& Susanne, C. (editors), Secular Growth Changes in Europe. Budapest: Eötvös University Press.

Carling, C., Bloomfield, J., Nelsen, L. \& Reilly, T. (2008). The role of motion analysis in elite soccer: Contemporary performance measurement techniques and work-rate data. Sports Medicine, 38, 839862.

Carling, C., le Gall, F., Reilly, T., \& Williams, A.M. (2009). Do anthropometric and fitness characteristics vary according to birth date distribution in elite youth academy soccer players? Scandinavian Journal of Medicine and Science in Sports, 19, 3-9.

Cazorla, G., Zazoui, M., Boussaidi, L., Zahi, B., \& Duclos, M. (2009). Étude des exigences physiologiques et biologiques du match de football et conséquences pour l'évaluation et la préparation physique du footballeur. In B. Zoudji (editor), Science et Football : Recherches et Connaissances Actuelles. Valenciennes : Presses Universataires de Valenciennes, pp. 349-355.

Centers for Disease Control and Prevention. (2000) National Center for Health Statistics CDC growth charts: United States. http://www.cdc.gov/growthcharts.htm.

Chtara, M., Chamari, K., Chaouachi, M.A., Koubaa, D., Feki, Y., Millet, G.P., \& Amri, M. (2005). Effects of intra-session concurrent endurance and strength training sequence on aerobic performance and capacity. British Journal of Sports Medicine, 39, 555-560.

Cunha, G., Lorenzi, T., Sapata, K., Lopes, A.L., Gaya, A.C., \& Oliveira, A. (2011) Effect of biological maturation on maximal oxygen uptake and ventilatory thresholds in soccer players: An allometric approach. Journal of Sports Sciences, 29, e-ahead of print.

Demoulin, F. (1998). Secular trend in France. In E.B. Bodzsar \& C. Susanne (editors), Secular Growth Changes in Europe. Budapest: Eötvös University Press, pp. 109-134. 
Durnin, J.V.G.R., \& Wormersley J. (1974). Body fat assessed from total body density and its estimation from skinfold thickness: measurements on 481 men and women aged from 16 to 72 years. British Journal of Nutrition, 32, 77-97.

Eveleth, P.B., \& Tanner, J.M. (1990) Worldwide Variation in Human Growth, $2^{\text {nd }}$ edition. Cambridge: Cambridge University Press.

Figueiredo, A.J., Coelho e Silva, M.J., \& Malina, R.M. (2011) Predictors of functional capacity and skill in youth soccer players. Scandinavian Journal of Medicine and Science in Sports, (PMID: 20136760, Epub ahead of print).

Figueiredo, A.J., Gonçalves, C.E., Coelho e Silva, M.J, Malina, R.M. (2009). Characteristics of youth soccer players who drop out, persist or move up. Journal of Sports Sciences, 27, 883-891.

Figueiredo, A.J., Gonçalves, C.E., Coelho e Silva, M.J., \& Malina, R.M. (2009). Youth soccer players, 1114 years: Maturity, size, function, skill and goal orientation. Annals of Human Biology, 36, 60-73.

Gil, S., Ruiz, F., Irazusta A., Gil, J., \& Irazusta, J. (2007a) Selection of young soccer players in terms of anthropometric and physiological factors. Journal of Sports Medicine and Physical Fitness, 47, $25-32$.

Greulich, W.W., \& Pyle, S.I. (1959) Radiographic Atlas of Skeletal Development of the Hand and Wrist, $2^{\text {nd }}$ edition. Stanford, CA: Stanford University Press.

Hopkins WG (2007). A spreadsheet to compare means of two groups. Sportscience 11, 22-23 (sportsci.org/2007/inbrief.htm\#xcl2).

Hopkins, W.G., Marshall, S.W., Batterham, A.M., \& Hanin, J. (2009) Progressive statistics for studies in sports medicine and exercise science. Medicine \& Science in Sports \& Exercise, 41, 3-12.

Le Gall, F., Carling, C., \& Reilly, T. (2007) Biological maturity and injury in elite youth football. Scandinavian Journal of Medicine and Science in Sports, 17, 564-572.

le Gall, F., Carling, C., Williams, M., \& Reilly, T. (2010). Anthropometric and fitness characteristics of international, professional and amateur male graduate soccer players from an elite youth academy. Journal of Science and Medicine in Sport, 13, 90-95. 
Malina R.M. (2003). Growth and maturity status of young soccer (football) players. In: Reilly T, Williams AM, eds. Science and soccer, 2nd edn (pp. 287-306). London: Routledge.

Malina, R.M. (2009) Ethnicity and biological maturation in sports medicine research. Scandinavian Journal of Medicine and Science in Sports, 19:1-2.

Malina, R.M. (2011). Skeletal age and age verification in youth sport. Sports Medicine, in press.

Malina, R.M., Coelho e Silva, M., \& Figueiredo, A.J. Growth and maturity status of youth soccer players. In M. Williams (editor), Science and Soccer: Developing Elite Players, (in press).

Malina, R.M., \& Geithner, C.A. (2011) Body composition of young athletes. America Journal of Lifestyle Medicine, 5, 262-278.

Malina, R.M., Bouchard, C., \& Bar-Or, O. (2004a). Growth, Maturation, and Physical Activity, $2^{\text {nd }}$ ed. Champaign, IL: Human Kinetics.

Malina, R.M., Cumming, S.P., Kontos, A.P., Eisenmann, J.E., Ribeiro, S., \& Aroso, J. (2005). Maturityassociated variation in sport-specific skills of youth soccer players aged 13-15 years. Journal of Sports Sciences, 23, 515-522.

Malina, R.M., Eisenmann, J.C., Cumming, S.P., Ribeiro, B., \& Aroso, J. (2004a). Maturity-associated variation in the growth and functional capacities of youth football (soccer) players 13-15 years. European Journal of Applied Physiology, 91, 555-562.

Malina, R.M., Ribeiro, B., Aroso, J., \& Cumming, S.P. (2007). Characteristics of youth soccer players aged 13-15 years classified by skill level. British Journal of Sports Medicine, 41, 290-295.

Meylan, C., Cronin, J., Oliver, J., \& Hughes, M. (2010). Talent identification in soccer: the role of maturity status on physical, physiological and technical characteristics. International Journal of Sports Science and Coaching, 5, 571-592.

Nevill, A, Holder, R, Watts, A (2009). The changing shape of "successful” professional footballers. Journal of Sports Sciences, 27, 419-426. 
Padez, C. (2003). Secular trend in stature in the Portuguese population (1904-2000). Annals of Human Biology, 30, 262-278.

Rebato, E. (1998) The studies on secular trend in Spain: A review. In E.B. Bodzsar, C. Susanne (editors), Secular Growth Changes in Europe. Budapest: Eötvös University Press, pp. 297-317.

Roche, A.F., Chumlea, C.W., \& Thissen, D. (1988) Assessing the Skeletal Maturity of the HandWrist: Fels Method. Springfield, IL: C.C. Thomas.

Reilly, T., Bangsbo, J., Franks, A. (2000) Anthropometric and physiological predispositions for elite soccer. Journal of Sports Science, 18, 669-683.

Reilly T, Williams AM, Nevill A, et al. A multidisciplinary approach to talent identification in soccer. J Sport Sci 2000; 18, 695-702

Sempé, M. (1995). Courbes de Croissance. http://www.sante.gouv.fr/IMG/pdf/carnet_de_sante.pdf (Accessed 1 May 2011).

Strudwick, T., \& Reilly T. (2001) Work-rate Profiles of Elite Premier League Football Players. Insight FA Coaches Association Journal, 4, 55-59.

Tanner, J.M., Whitehouse, R.H., Cameron, N., Marshall, W.A., Healy, M.J.R., \& Goldstein, H. (1983) Assessment of Skeletal Maturity and Prediction of Adult Height, $2^{\text {nd }}$ edition. New York: Academic Press.

Vaeyens, R., Lenoir, M., Williams, A.M., \& Philippaerts R.M. (2008) Talent identification and development programmes in sport: current models and future directions. Sports Medicine, 38, 703-714. Vaeyens, R., Malina, R.M., Janssens, M., Van Renterghem, B., Bourgois, J., Vrijens, J., Philippaerts R.M. (2006) A multidisciplinary selection model for youth soccer: the Ghent Youth Soccer Project. British Journal of Sports Medicine, 40, 928-934.

Williams, A.M., \& Reilly, T. (2000). Talent identification and development in soccer. Journal of Sports Sciences. 18, 657-667. 
Table 1. Sample sizes, means (M) and standard deviations (SD) for chronological age (CA), skeletal age (SA), difference between SA and CA (SA-

CA), body size, estimated fatness and functional characteristics of players by years from 1992 and 2001 and for the total sample.

\begin{tabular}{|c|c|c|c|c|c|c|c|c|c|c|c|c|c|}
\hline \multirow[b]{2}{*}{ Year } & \multirow[b]{2}{*}{$\mathrm{n}$} & \multicolumn{2}{|c|}{ CA, yrs } & \multicolumn{2}{|c|}{ SA, yrs } & \multicolumn{2}{|c|}{ SA-CA, yrs } & \multicolumn{2}{|c|}{ Height, cm } & \multicolumn{2}{|c|}{ Weight, kg } & \multicolumn{2}{|c|}{ Fat, \% } \\
\hline & & M & $\mathrm{SD}$ & $\mathrm{M}$ & $\mathrm{SD}$ & M & $\mathrm{SD}$ & M & SD & $\mathrm{M}$ & $\mathrm{SD}$ & $\mathrm{MS}$ & $\mathrm{SD}$ \\
\hline $1992^{1}$ & 13 & 13.8 & 0.2 & 13.9 & 1.1 & 0.10 & 1.11 & 166.8 & 10.1 & 55.9 & 10.6 & 13.2 & 2.3 \\
\hline 1994 & 15 & 13.8 & 0.3 & 14.4 & 1.3 & 0.68 & 1.16 & 166.0 & 7.5 & 54.5 & 7.4 & 12.42 & 2.1 \\
\hline 1995 & 21 & 13.8 & 0.2 & 13.9 & 1.2 & 0.15 & 1.03 & 164.0 & 9.9 & 54.0 & 9.5 & 12.6 & 1.9 \\
\hline 1996 & 25 & 13.4 & 0.4 & 13.2 & 0.9 & -0.16 & 0.93 & 158.7 & 8.0 & 47.3 & 7.5 & 13.8 & 1.9 \\
\hline 1997 & 25 & 13.6 & 0.6 & 13.6 & 1.7 & 0.03 & 1.38 & 162.0 & 9.3 & 49.8 & 10.2 & 11.8 & 2.4 \\
\hline 1998 & 24 & 13.3 & 0.2 & 14.1 & 1.6 & 0.81 & 1.60 & 164.0 & 8.1 & 52.8 & 8.1 & 12.0 & 2.6 \\
\hline 1999 & 23 & 13.3 & 0.2 & 13.3 & 1.2 & 0.13 & 1.15 & 163.0 & 9.0 & 51.0 & 9.9 & 11.8 & 2.5 \\
\hline $2001^{2}$ & 12 & 13.3 & 0.4 & 14.0 & 1.6 & 0.75 & 1.65 & 167.7 & 10.8 & 55.9 & 11.2 & 11.3 & 2.2 \\
\hline \multirow[t]{4}{*}{ Total } & 158 & 13.5 & 0.4 & 13.7 & 1.4 & 0.25 & 1.29 & 163.4 & 9.2 & 52.0 & 9.5 & 12.42 & 2.3 \\
\hline & & \multirow{2}{*}{\multicolumn{2}{|c|}{$\begin{array}{l}\mathrm{VO}_{2} \max \\
\mathrm{ml} / \mathrm{kg} / \mathrm{min}\end{array}$}} & \multirow{2}{*}{\multicolumn{2}{|c|}{$\begin{array}{l}\text { Vertical } \\
\text { Jump, cm }\end{array}$}} & \multicolumn{6}{|c|}{ Sprints, sec } & \multirow{2}{*}{\multicolumn{2}{|c|}{$\begin{array}{l}\text { MAP, } \\
\text { watts }\end{array}$}} \\
\hline & & & & & & 10 & & & $\mathrm{~m}$ & & $0 \mathrm{~m}$ & & \\
\hline & $\mathrm{n}$ & M & $\mathrm{SD}$ & $\mathrm{M}$ & $\mathrm{SD}$ & M & $\mathrm{SD}$ & $\mathrm{M}$ & SD & M & $\mathrm{SD}$ & $\mathrm{M}$ & $\mathrm{SD}$ \\
\hline $1992^{1}$ & 13 & 57.7 & 2.6 & 45.1 & 7.6 & 1.94 & 0.09 & 3.31 & 0.12 & 5.79 & 0.24 & 1925 & 519 \\
\hline 1994 & 15 & 56.6 & 2.2 & 43.5 & 5.9 & 1.93 & 0.08 & 3.27 & 0.13 & 5.77 & 0.23 & 1807 & 411 \\
\hline 1995 & 21 & 57.1 & 3.3 & 44.4 & 6.3 & 1.93 & 0.05 & 3.30 & 0.12 & 5.85 & 0.25 & 1768 & 513 \\
\hline 1996 & 25 & 58.4 & 3.2 & 41.7 & 5.6 & 1.99 & 0.09 & 3.39 & 0.13 & 5.97 & 0.26 & 1457 & 364 \\
\hline 1997 & 25 & 57.9 & 3.0 & 43.1 & 6.2 & 1.96 & 0.10 & 3.35 & 0.16 & 6.00 & 0.35 & 1507 & 570 \\
\hline
\end{tabular}




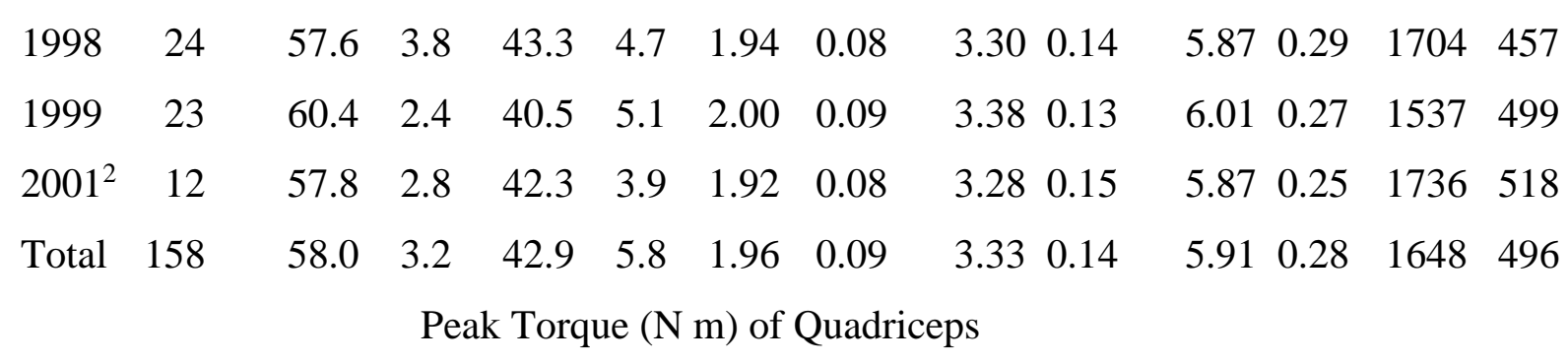


Table 2. Results of MANCOVA with age at the covariate comparing player characteristics across three selection periods: 1992-1995, 1996-1998 and 1999-2003.

\begin{tabular}{llll}
\hline Characteristic & $F$ & p & Significant Pairwise Comparisons \\
\hline Skeletal age (SA) & 0.32 & & \\
SA-CA difference & 0.31 & & \\
Height & 1.96 & & \\
Weight & 2.51 & & \\
\% Fat & 3.48 & $<0.05$ & $92-95>99-03$ \\
VO2max & 7.01 & $<0.01$ & $99-03>92-95 \& 96-98$ \\
Vertical jump & 1.98 & & \\
Sprint, 10m & & \\
Sprint, 20m & & & \\
Sprint, 40m & & & \\
Anaerobic power & 2.07 & & \\
Peak Torque, Quadriceps: & 2.37 & & \\
Dominant leg 1.05 rad/s & 3.13 & $<0.05$ & \\
Dominant leg 4.19 rad/s & 2.77 & & \\
Non-dominant leg 1.05 rad/s & 0.07 & & \\
Non-dominant leg 4.19 rad/s & 0.71 & & \\
& & &
\end{tabular}


Table 3. Sample sizes and means (M) and standard deviations (SD) for chronological age (CA), skeletal age (SA), SA-CA difference, body size, estimated fatness and functional characteristics of players by skeletal maturity status and results of MANOVA.

\begin{tabular}{|c|c|c|c|c|c|c|c|}
\hline & \multicolumn{6}{|c|}{ Maturity Status Groups } & \multirow[b]{3}{*}{$\mathrm{F}$} \\
\hline & \multicolumn{2}{|c|}{$\begin{array}{c}\text { Late } \\
(\mathrm{n}=26,22)^{1}\end{array}$} & \multicolumn{2}{|c|}{$\begin{array}{l}\text { On time } \\
(n=98,93)\end{array}$} & \multicolumn{2}{|c|}{$\begin{array}{l}\text { Early } \\
(\mathrm{n}=34,31)\end{array}$} & \\
\hline & M & SD & M & $\mathrm{SD}$ & M & SD & \\
\hline SA, yrs & 12.0 & 0.5 & 13.6 & 0.7 & 15.6 & 1.0 & \\
\hline SA-CA difference, yrs & -1.5 & 0.3 & 0.1 & 0.6 & 2.1 & 0.8 & \\
\hline CA, yrs & 13.5 & 0.3 & 13.5 & 0.4 & 13.5 & 0.6 & 0.17 \\
\hline Height, cm & 152.9 & 5.1 & 163.5 & 8.2 & 171.0 & 6.2 & $44.32 *$ \\
\hline Weight, kg & 40.6 & 3.4 & 52.0 & 8.2 & 60.6 & 6.6 & $55.87 *$ \\
\hline Fat, \% & 11.5 & 2.5 & 12.4 & 2.2 & 12.9 & 2.5 & 2.89 \\
\hline $\mathrm{VO}_{2} \max , \mathrm{ml} / \mathrm{kg} / \mathrm{min}$ & 58.1 & 3.0 & 57.9 & 3.3 & 58.3 & 3.0 & 0.12 \\
\hline Vertical jump, cm & 39.4 & 5.2 & 42.9 & 5.8 & 45.5 & 4.8 & $8.83 *$ \\
\hline Sprint $10 \mathrm{~m}$, sec & 2.01 & 0.08 & 1.96 & 0.09 & 1.90 & 0.60 & $14.11 *$ \\
\hline Sprint 20m, sec & 3.44 & 0.11 & 3.34 & 0.13 & 3.23 & 0.12 & $21.40 *$ \\
\hline Sprint 40m, sec & 6.16 & 0.21 & 5.92 & 0.27 & 5.67 & 0.17 & $28.58 *$ \\
\hline Anaerobic power, watts & 1099 & 225 & 1629 & 431 & 2123 & 337 & $52.22 *$ \\
\hline \multicolumn{8}{|l|}{ Peak torque, $\mathrm{N}$ m } \\
\hline Dominant $1.05 \mathrm{rad} / \mathrm{s}$ & 124 & 37 & 159 & 27 & 191 & 27 & $36.05 *$ \\
\hline Dominant $4.19 \mathrm{rad} / \mathrm{s}$ & 70 & 18 & 92 & 17 & 112 & 20 & $28.59 *$ \\
\hline
\end{tabular}




\begin{tabular}{lrrrrrrr} 
Non-dominant $1.05 \mathrm{rad} / \mathrm{s}$ & 132 & 27 & 159 & 29 & 190 & 25 & $36.47^{*}$ \\
Non-dominant $4.19 \mathrm{rad} / \mathrm{s}$ & 75 & 15 & 94 & 19 & 115 & 20 & $29.77^{*}$ \\
\hline
\end{tabular}

${ }^{1}$ The second number refers to sample sizes for the isokinetic strength tests. $* \mathrm{p}<0.001$ 
Table 4. Sample sizes and means (M) and standard deviations (SD) for chronological age (CA), skeletal age (SA), SA-CA ratio, body size, fatness and physical fitness of players by position and results of MANOVA.

\begin{tabular}{|c|c|c|c|c|c|c|c|c|c|c|}
\hline & \multicolumn{2}{|c|}{$\begin{array}{c}\text { Goalkeeper } \\
(\mathrm{G}, \mathrm{n}=23,20)^{1}\end{array}$} & \multicolumn{2}{|c|}{$\begin{array}{c}\text { Defender } \\
(\mathrm{D}, \mathrm{n}=31,29)\end{array}$} & \multicolumn{2}{|c|}{$\begin{array}{c}\text { Midfielder } \\
(\mathrm{M}, \mathrm{n}=60,55)\end{array}$} & \multicolumn{2}{|c|}{$\begin{array}{c}\text { Forward } \\
(\mathrm{F}, \mathrm{n}=44,42)\end{array}$} & \multirow[b]{2}{*}{$\mathrm{F}$} & \multirow{2}{*}{$\begin{array}{l}\text { Significant } \\
\text { Comparisons }\end{array}$} \\
\hline & M & SD & M & SD & M & SD & M & SD & & \\
\hline CA, yrs & 13.4 & 0.3 & 13.6 & 0.25 & 13.5 & 0.5 & 13.5 & 0.4 & 0.85 & \\
\hline SA, yrs & 14.0 & 0.9 & 14.2 & 1.4 & 13.3 & 1.2 & 13.9 & 1.5 & $4.12 *$ & $\mathrm{D}>\mathrm{M}$ \\
\hline SA-CA, yrs & 0.55 & 0.87 & 0.66 & 1.29 & -0.18 & 1.06 & 0.40 & 1.58 & $4.08^{*}$ & $\mathrm{D}>\mathrm{M}$ \\
\hline Height, $\mathrm{cm}$ & 168.0 & 8.1 & 168.3 & 9.3 & 160.2 & 8.7 & 161.9 & 8.2 & $8.83^{*}$ & $\mathrm{D}=\mathrm{G}>\mathrm{F}=\mathrm{M}$ \\
\hline Weight, kg & 57.3 & 9.5 & 56.8 & 8.8 & 48.5 & 8.8 & 50.6 & 8.3 & $9.48^{*}$ & $\mathrm{G}=\mathrm{D}>\mathrm{F}>\mathrm{M}$ \\
\hline Fat, \% & 12.8 & 2.1 & 12.9 & 2.1 & 12.1 & 2.5 & 12.1 & 2.4 & 1.26 & \\
\hline $\mathrm{VO}_{2} \max , \mathrm{ml} / \mathrm{kg}$ & 55.1 & 3.2 & 58.5 & 3.0 & 58.9 & 3.0 & 58.1 & 2.7 & $9.61 *$ & $\mathrm{M}=\mathrm{D}=\mathrm{F}>\mathrm{G}$ \\
\hline Vert jump, cm & 43.7 & 5.8 & 43.7 & 5.2 & 40.6 & 5.2 & 44.8 & 6.0 & $5.50 *$ & $\mathrm{~F}>\mathrm{M}$ \\
\hline Sprint $10 \mathrm{~m}, \mathrm{sec}$ & 1.97 & 0.08 & 1.94 & 0.09 & 1.98 & 0.08 & 1.93 & 0.08 & $4.58 *$ & $\mathrm{~F}>\mathrm{M}$ \\
\hline Sprint $20 \mathrm{~m}, \mathrm{sec}$ & 3.34 & 0.14 & 3.31 & 0.14 & 3.38 & 0.13 & 3.27 & 0.14 & $5.27 *$ & $\mathrm{~F}>\mathrm{M}$ \\
\hline Sprint $40 \mathrm{~m}$, sec & 5.94 & 0.31 & 5.84 & 0.24 & 6.01 & 0.26 & 5.81 & 0.28 & $5.24^{*}$ & $\mathrm{~F}=\mathrm{D}>\mathrm{G}=\mathrm{M}$ \\
\hline AP, watts & 1794 & 515 & 1868 & 479 & 1451 & 444 & 1687 & 479 & $6.60 *$ & $\mathrm{G}=\mathrm{F}=\mathrm{D}>\mathrm{M}$ \\
\hline \multicolumn{11}{|l|}{ Peak torque, $\mathrm{N} \mathrm{m}^{2}$} \\
\hline Dom $1.05 \mathrm{rad} / \mathrm{s}$ & 170 & 30 & 172 & 43 & 153 & 32 & 158 & 33 & 2.60 & \\
\hline Dom $4.19 \mathrm{rad} / \mathrm{s}$ & 99 & 21 & 97 & 24 & 87 & 20 & 95 & 20 & 2.45 & \\
\hline $\mathrm{N}-$ dom $1.05 \mathrm{rad} / \mathrm{s}$ & 177 & 34 & 174 & 35 & 151 & 32 & 160 & 27 & $5.10^{*}$ & $\mathrm{G}=\mathrm{D}>\mathrm{M}, \mathrm{F}=\mathrm{M}$ \\
\hline $\mathrm{N}-$ dom $240 \mathrm{rad} / \mathrm{s}$ & 103 & 25 & 99 & 22 & 91 & 22 & 96 & 21 & 1.93 & \\
\hline
\end{tabular}

$* \mathrm{p}<0.01$ 
${ }^{1}$ The second number refers to sample sizes for the strength tests.

${ }^{2}$ Dom $=$ dominant leg, $\mathrm{N}$-dom $=$ non-dominant leg 
Table 5. Results of the MANCOVA of functional capacities of players by position, controlling for skeletal maturation (SA-CA difference), height and weight; adjusted means (M) and standard errors (SE); and results of post hoc comparisons.

\begin{tabular}{|c|c|c|c|c|c|c|c|c|c|c|}
\hline & \multirow[b]{2}{*}{$\mathrm{F}$} & \multicolumn{2}{|c|}{$\begin{array}{l}\text { Goalkeeper } \\
(\mathrm{G}, \mathrm{n}=23)\end{array}$} & \multicolumn{2}{|c|}{$\begin{array}{l}\text { Defender } \\
(D, n=31)\end{array}$} & \multicolumn{2}{|c|}{$\begin{array}{l}\text { Midfielder } \\
(\mathrm{M}, \mathrm{n}=60)\end{array}$} & \multicolumn{2}{|c|}{$\begin{array}{l}\text { Forward } \\
(\mathrm{F}, \mathrm{n}=44)\end{array}$} & \multirow{2}{*}{$\begin{array}{c}\text { Significant } \\
\text { Comparisons }\end{array}$} \\
\hline & & $\mathrm{M}$ & SE & $\mathrm{M}$ & SE & $\mathrm{M}$ & SE & $\mathrm{M}$ & SE & \\
\hline $\mathrm{VO}_{2} \max , \mathrm{ml} / \mathrm{kg}$ & $8.77 *$ & 55.3 & 0.6 & 58.5 & 0.5 & 58.9 & 0.4 & 57.9 & 0.4 & $\mathrm{M}=\mathrm{D}=\mathrm{F}>\mathrm{G}$ \\
\hline Vert jump, cm & $4.32 *$ & 42.6 & 1.1 & 42.6 & 1.0 & 41.4 & 0.7 & 45.1 & 0.8 & $\mathrm{~F}>\mathrm{M}, \mathrm{F}=\mathrm{G}=\mathrm{D}$ \\
\hline Sprint $10 \mathrm{~m}$, sec & $4.68 *$ & 1.99 & 0.02 & 1.96 & 0.01 & 1.97 & 0.01 & 1.92 & 0.01 & $\mathrm{~F}>\mathrm{G}=\mathrm{M}, \mathrm{F}=\mathrm{D}, \mathrm{M}=\mathrm{D}=\mathrm{C}$ \\
\hline Sprint $20 \mathrm{~m}$, sec & $6.52 *$ & 3.38 & 0.02 & 3.35 & 0.02 & 3.35 & 0.02 & 3.27 & 0.02 & $\mathrm{~F}>\mathrm{M}=\mathrm{D}=\mathrm{G}$ \\
\hline Sprint $40 \mathrm{~m}$, sec & $6.99 *$ & 6.03 & 0.04 & 5.94 & 0.04 & 5.93 & 0.03 & 5.79 & 0.03 & $\mathrm{~F}>\mathrm{M}=\mathrm{D}=\mathrm{G}$ \\
\hline $\mathrm{AP}$, watts & $4.67 *$ & 1551 & 45 & 1637 & 38 & 1623 & 28 & 1742 & 32 & $\mathrm{~F}>\mathrm{G}=\mathrm{D}=\mathrm{M}, \mathrm{F}>\mathrm{M}$ \\
\hline \multicolumn{11}{|l|}{ Peak torque, $\mathrm{N} \mathrm{m}^{1}$} \\
\hline Dom $1.05 \mathrm{rad} / \mathrm{s}$ & 0.29 & 157 & 5 & 159 & 4 & 163 & 3 & 161 & 4 & \\
\hline Dom $4.19 \mathrm{rad} / \mathrm{s}$ & 1.94 & 91 & 3 & 89 & 3 & 93 & 2 & 97 & 2 & \\
\hline $\mathrm{N}$-dom $1.05 \mathrm{rad} / \mathrm{s}$ & 0.32 & 165 & 5 & 162 & 4 & 160 & 3 & 163 & 3 & \\
\hline $\mathrm{N}-$ dom $4.19 \mathrm{rad} / \mathrm{s}$ & 2.01 & 95 & 3 & 90 & 3 & 97 & 2 & 98 & 2 & \\
\hline
\end{tabular}


Table 6. Means (M) and standard deviations (SD) for chronological age (CA), skeletal age (SA), SA-CA difference, body size, estimated fatness and functional characteristics at baseline of players grouped by subsequent status in soccer and results of MANOVA.

\begin{tabular}{|c|c|c|c|c|c|c|}
\hline & \multicolumn{2}{|c|}{$\begin{array}{l}\text { Non-Professional } \\
\qquad(n=90,88)\end{array}$} & \multicolumn{2}{|c|}{$\begin{array}{c}\text { Professional } \\
(n=68,58)\end{array}$} & \multirow[b]{2}{*}{$\mathrm{F}$} & \multirow[b]{2}{*}{$\mathrm{p}$} \\
\hline & M & $\mathrm{SD}$ & M & $\mathrm{SD}$ & & \\
\hline CA, yrs & 13.6 & 0.5 & 13.4 & 0.3 & 3.35 & $=0.07$ \\
\hline SA, yrs & 13.9 & 1.5 & 13.6 & 1.2 & 1.47 & \\
\hline SA-CA difference, yrs & 0.32 & 1.35 & 0.17 & 1.20 & 0.53 & \\
\hline Height, cm & 162.1 & 8.9 & 165.1 & 9.3 & 4.42 & $<0.05$ \\
\hline Weight, kg & 50.8 & 9.1 & 53.6 & 9.7 & 3.46 & $=0.07$ \\
\hline Fat, \% & 12.4 & 2.2 & 12.3 & 2.5 & 0.02 & \\
\hline $\mathrm{VO}_{2} \max , \mathrm{ml} / \mathrm{kg} / \mathrm{min}$ & 57.6 & 3.3 & 58.6 & 2.9 & 3.39 & $=0.07$ \\
\hline Vertical jump, cm & 42.9 & 5.8 & 45.5 & 4.8 & 0.27 & \\
\hline Sprint $10 \mathrm{~m}, \mathrm{sec}$ & 1.96 & 0.08 & 1.96 & 0.09 & 0.02 & \\
\hline Sprint $20 \mathrm{~m}, \mathrm{sec}$ & 3.33 & 0.14 & 3.33 & 0.15 & 0.01 & \\
\hline Sprint $40 \mathrm{~m}$, sec & 5.90 & 0.27 & 5.91 & 0.30 & 0.06 & \\
\hline Anaerobic power, watts & 1612 & 486 & 1697 & 508 & 1.15 & \\
\hline \multicolumn{7}{|l|}{ Peak torque, $\mathrm{N}$ m } \\
\hline Dominant $1.05 \mathrm{rad} / \mathrm{s}$ & 158 & 36 & 164 & 33 & 1.05 & \\
\hline Dominant $4.19 \mathrm{rad} / \mathrm{s}$ & 92 & 23 & 95 & 19 & 0.88 & \\
\hline
\end{tabular}




\begin{tabular}{lrrrrr} 
Non-dominant $1.05 \mathrm{rad} / \mathrm{s}$ & 161 & 32 & 163 & 35 & 0.04 \\
Non-dominant 4.19 rad/s & 95 & 23 & 98 & 22 & 0.66 \\
\hline
\end{tabular}

${ }^{1}$ The second number refers to sample sizes for the strength tests. $* \mathrm{p}<0.001$ 